\title{
Shake Table Study on the Effect of Mainshock-Aftershock Sequences on Structures with SFSI
}

\author{
Xiaoyang Qin and Nawawi Chouw \\ Department of Civil and Environmental Engineering, The University of Auckland, 20 Symonds Street, Auckland, New Zealand \\ Correspondence should be addressed to Xiaoyang Qin; xqin009@aucklanduni.ac.nz
}

Received 10 July 2017; Accepted 19 September 2017; Published 23 October 2017

Academic Editor: Ivo Caliò

Copyright (C) 2017 Xiaoyang Qin and Nawawi Chouw. This is an open access article distributed under the Creative Commons Attribution License, which permits unrestricted use, distribution, and reproduction in any medium, provided the original work is properly cited.

\begin{abstract}
Observations from recent earthquakes have emphasised the need for a better understanding of the effects of structure-footing-soil interaction on the response of structures. In order to incorporate the influences of soil, a laminar box can be used to contain the soil during experiments. The laminar box simulates field boundary conditions by allowing the soil to shear during shake table tests. A holistic response of a structure and supporting soil can thus be obtained by placing a model structure on the surface of the soil in the laminar box. This work reveals the response of structure with SFSI under mainshock and aftershock earthquake sequences. A large ( $2 \mathrm{~m}$ by $2 \mathrm{~m}$ ) laminar box, capable of simulating the behaviour of both dry and saturated soils, was constructed. A model structure was placed on dry sand in the laminar box. The setup was excited by a sequence of earthquake excitations. The first excitation was used to obtain the response of the model on sand under the mainshock of an earthquake. The second and third excitations represented the first and second aftershocks, respectively.
\end{abstract}

\section{Introduction}

During an earthquake, the movement of soil causes movement of structures and this structural response, in turn, influences the movement of soil. This structure-footingsoil interaction (SFSI) can cause the seismic response of a structure to be different from that of an identical structure with an idealised fixed base assumption. This process may also cause the response of the soil to be different from what would be measured under free-field conditions, that is, without the structure. Observations from recent earthquakes, including those from the 2010-2011 Canterbury earthquakes, have identified a significant influence that the behaviour of soil can have on the overall seismic performance of structures.

By carrying out experiments, a more realistic simulation of the structural response with SFSI can be achieved. This not only allows researchers to understand the effects of SFSI but also it enables validation and improvement of numerical models. An early contribution to the understanding of SFSI was the presented example by Taylor et al. [1], where cyclic displacements were applied to a number of model footings seated on clay and sand. The results suggested that the soil beneath the footing can be intentionally designed to deform beyond the elastic limit in strong earthquakes. This nonlinear soil behaviour can activate rigid body movements of the structure. As a consequent, a development of plastic hinge in the structure could be avoided. As discussed by Veletsos and Meek [2], the flexible ground can act as a damper by absorbing a large part of the vibration energy arising from earthquakes and thus can reduce the seismic response of a structure. Larkin [3] also concluded that the flexibility of the supporting soil can lengthen the vibration period of the structure-footing-soil system and result in a variation of structural response when compared to those obtained from analyses without considering SFSI.

On the other hand, the deformation of soil under footing rotation can sometimes result in the temporary uplift of footings. Deng et al. [4,5] conducted centrifuge tests on single-degree-of-freedom (SDOF) bridge structures of various footing sizes, and Algie et al. [6] carried out dynamic field tests on a rocking shallow footing. The results of these investigations emphasised that footing uplift and nonlinear soil behaviour should be taken into consideration in seismic design. Recently, the effects of uplift on the response of liquid 
storage tanks structures and nuclear plants have also been studied [7-11]. Qin et al. [12] studied the influence of footing uplift on the induced vibration of secondary structures. It was reported that footing uplift can not only reduce the response of structures but also reduce the induced vibrations of secondary structures. Larkin et al. [13] studied the response of structure considering adjacent structures.

Experimental simulation of the structural response with uplift on soil support depends on the correct replication of soil response during earthquakes. This can be achieved throughout the use of a laminar box. Laminar boxes are designed to simulate soil deformation conditions in situ and thus allow the soil to undergo shear deformation during a shake table test. Some of the characteristics that make laminar box tests preferable to other experimental methods, for example, field tests, are as follows [14]:

(i) The ability to simulate boundary conditions of soil in situ

(ii) The capacity to test soil specimens that are larger than the typical small-scale laboratory experiments like triaxial test

(iii) Being able to explore the behaviour of soils in nonuniform, layered, and sloping sites

(iv) The ability to reproduce the seismic response of structure and soil as one holistic system

Researchers have designed various types of laminar boxes in the past. A very simple laminar box was utilised by Latha and Krishna [15] in their study. This small box was rectangular in plan with internal dimensions of $0.5 \mathrm{~m} \times 1 \mathrm{~m} \times 0.8 \mathrm{~m}$. The box consisted of 15 laminar layers, constructed from pieces of hollow aluminium rectangular sections. The layers were separated by linear roller bearings to minimise friction. A more complicated laminar box was described by Ueng et al. [16]. This box was designed to undergo two-dimensional shaking and hence was called a biaxial laminar box. The box was rectangular in plan and had internal dimensions of $1.88 \mathrm{~m}$ $\times 1.88 \mathrm{~m} \times 1.52 \mathrm{~m}$. It was made up of 15 horizontal layers and had a special sliding system which allowed movements in the horizontal plane. The layers were supported by a rigid steel structure which surrounded the entire box. The inside of this biaxial box was sealed with a $2 \mathrm{~mm}$ thick silicone rubber membrane which allowed for the testing of both dry and wet soils.

Study of structural response with SFSI focuses on the effect of the mainshock of the earthquake. Although the consequence of aftershock has been reported after many earthquake events, the structural response with SFSI in the aftershock event has not been studied. In this study, which is a part of the doctoral thesis of Qin [14], a laminar box large in horizontal areal extent was constructed. A SDOF model placed on sand in the box was considered. The responses of the model under the mainshock and aftershocks of an earthquake were compared.

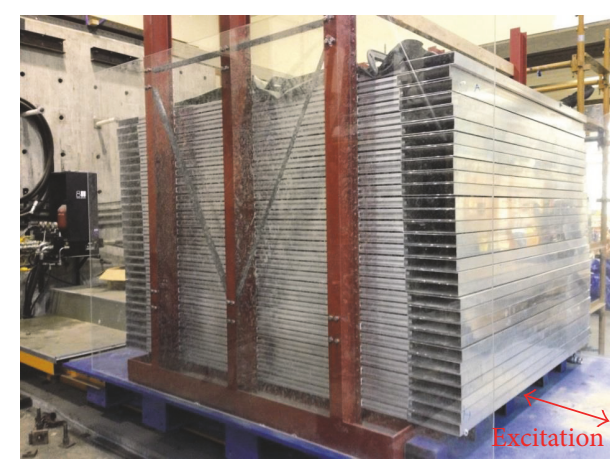

Figure 1: The laminar box on the shake table.

\section{Design of Large Laminar Box}

A laminar box should accommodate the movement of soil and neither resists nor promotes soil displacement. The design of the large laminar box involved identification and consideration of the issues important to the performance of the box. These included inertia, friction, membrane effects, and boundary/corner effects [17]. The inertia of a heavy container can alter the movement of soil within the container that the soil-container system no longer simulates the soil movements in free-field condition. To minimise this effect, the laminar layers should be of relatively low mass [16]. In view of this, a lightweight material had to be chosen for the laminar layers. To ensure that the box would not resist soil movements, a sliding system had to be developed to allow the layers to move with as little frictional resistance as possible. Since the laminar box will also be used to test saturated soils to study the effect of soil liquefaction, a waterproof membrane was used. It had to be designed of sufficiently high flexibility to avoid any influence on the response of the soil [17].

The boundary effects are typically localised along the edges of the box. At the centre of the soil mass, the effects are usually not significant at the centre. Thus, the laminar box was designed with a large surface area to ensure that a suitable volume of soil at the centre of the overall mass would remain unaffected by boundary/corner effects. Other factors such as the availability of materials, cost, and ease of construction/repair were also considered during the design process. Active earth pressures $[18,19]$ were computed assuming that the entire box was filled with saturated soil. All components of the box were then designed to withstand the predicted loading. The final assembly of the large laminar box is shown in Figure 1. This box will be placed on a shake table and excited along its longitudinal axis. The final part of the design involved evaluating the structural integrity of all components of the box.

The laminar box has internal dimensions of $2 \mathrm{~m} \times 2 \mathrm{~m} \times$ $2 \mathrm{~m}$. Each laminar layer can move horizontally, in the direction of the excitation, up to $175 \mathrm{~mm}$. The soil inside the box can undergo a maximum shear strain of approximately $9 \%$, which is enough to simulate the in site epicentral displacement of soil under a large earthquake event. The box consists of three major components, that is, the base including barrier columns, the stack of laminar layers, and the membrane. 


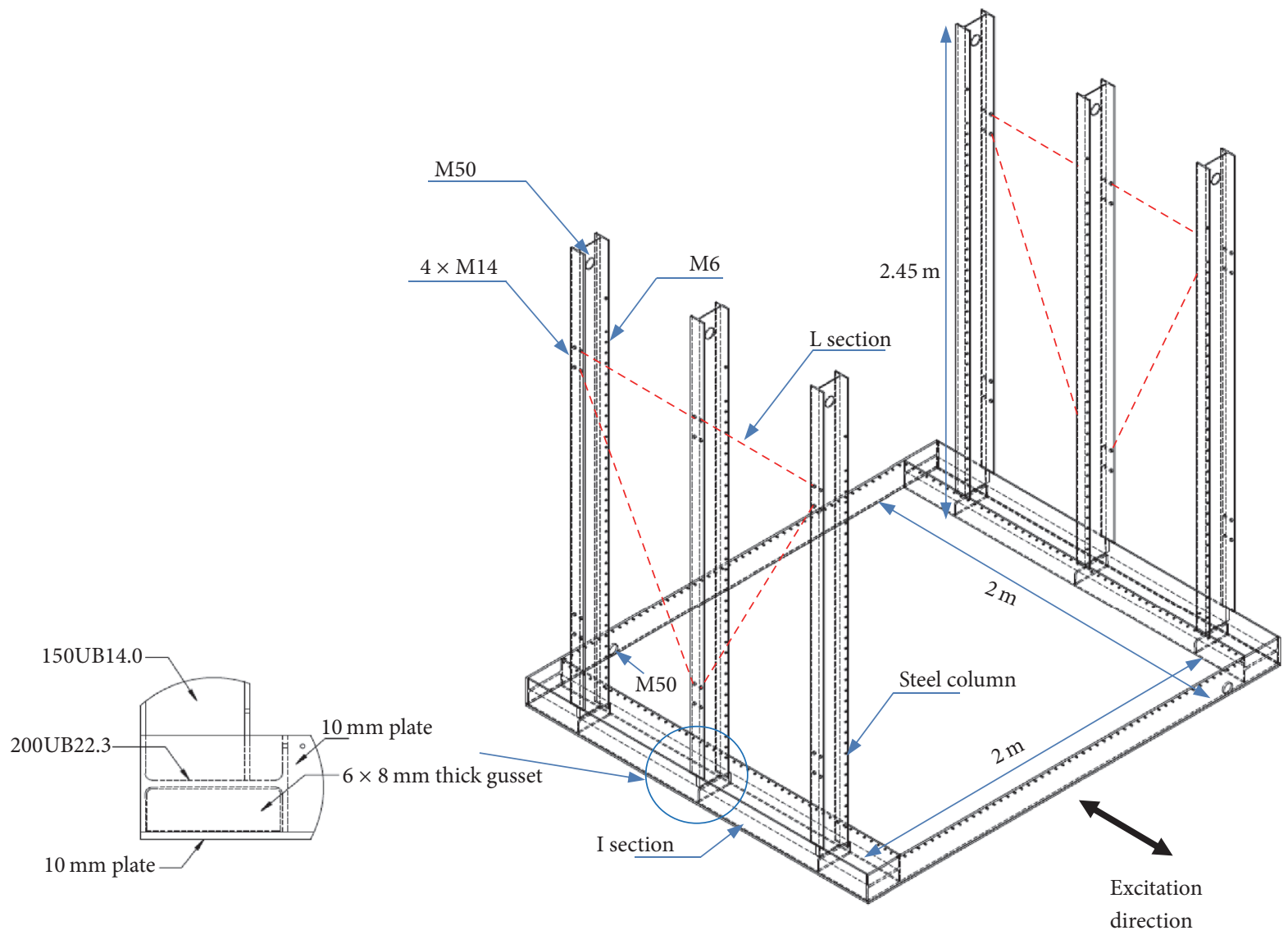

Figure 2: Details of the base and barrier columns.

2.1. Base and Barriers. The details of the base are shown in Figure 2. The base has internal dimensions of $2 \mathrm{~m} \times 2 \mathrm{~m} \times$ $0.235 \mathrm{~m}$ and is made of $10 \mathrm{~mm}$ steel plate. Steel I-sections (200UB22.3) are welded horizontally on the transverse sides of the base. Three columns are welded onto the I-sections. These $2.45 \mathrm{~m}$ high 150UB14.0 columns also provide the main structural strength of the box. This height is selected for the preparation of soil specimen (discussed in Section 2.4).

Rigid steel L sections brace the three columns (see reddashed line in Figure 2). These members minimise vibration of the columns in the longitudinal shaking direction. A row of M6 holes, at $53 \mathrm{~mm} \mathrm{c/c}$, is drilled on the flange of the columns that face the inside of the box. Each hole will be used to fix a ball bearing for supporting a laminar layer. An $8 \mathrm{~mm}$ thick gusset is welded on the horizontal I-section directly under each column to facilitate load transfer to the base.

2.2. Laminar Layers. Thirty thin laminar layers are used. Each of these layers is composed of a lightweight aluminium alloy that minimises the mass. Figure 3 shows the construction of the laminar layers. Each laminar layer is a frame made of a combination of $\mathrm{X}$-shaped sections and $250 \mathrm{~mm} \times 50 \mathrm{~mm}$ $\times 3 \mathrm{~mm}$ rectangular hollow sections. It was decided to use $\mathrm{x}-$ shaped sections as these sections have built-in tracks in which ball bearings are used to support the laminar layer. In this way, ball bearings are not installed between laminar layers, and the gap between the laminar layers is thus minimised. The $\mathrm{x}$-shaped sections and rectangular hollow sections are bolted together using M12 bolts to form each layer.

Each layer is separated and supported by ball bearings fixed on the external columns. The ball bearings allow the layers to move relative to one other with little frictional resistance. A Teflon washer is provided between the $\mathrm{x}$-shaped sections and the columns in order to reduce friction, thereby minimising resistance from the columns to the sliding of the laminar layers. As described in the previous section, the spacing between the holes for the ball bearings is $53 \mathrm{~mm}$. The total thickness of the laminar layer is $50 \mathrm{~mm}$ (i.e., the height of the hollow section). Thus the gap between laminar layers is controlled to within $3 \mathrm{~mm}$.

2.3. Membrane. The third major component of the large laminar box is the membrane that lines the inside of the box. While most other laminar boxes, such as the one developed by Ueng et al. [16], have utilised a silicone rubber membrane, the membrane in this box is made of a flexible and durable PVC fabric. It was chosen to minimise the resistance to the movement of sand during shear. The fabric was designed to fold/unfold as sand moves against it rather than to stretch like a conventional silicone rubber membrane. The membrane is made from a trapezium-shaped piece of fabric. The bottom of the trapezium has a length equal to the inner perimeter of the 

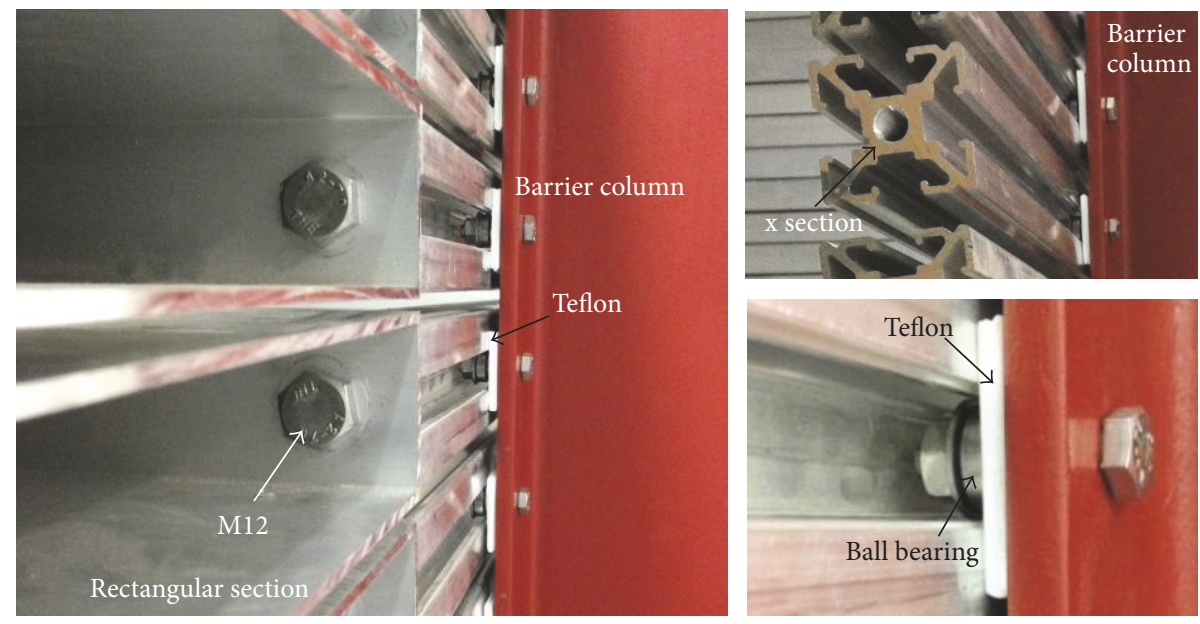

FIGURE 3: Construction of the laminar layers.

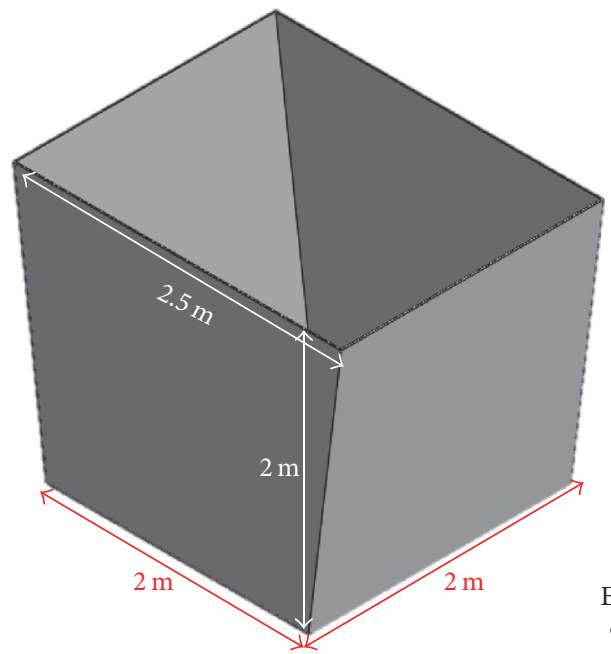

(a)

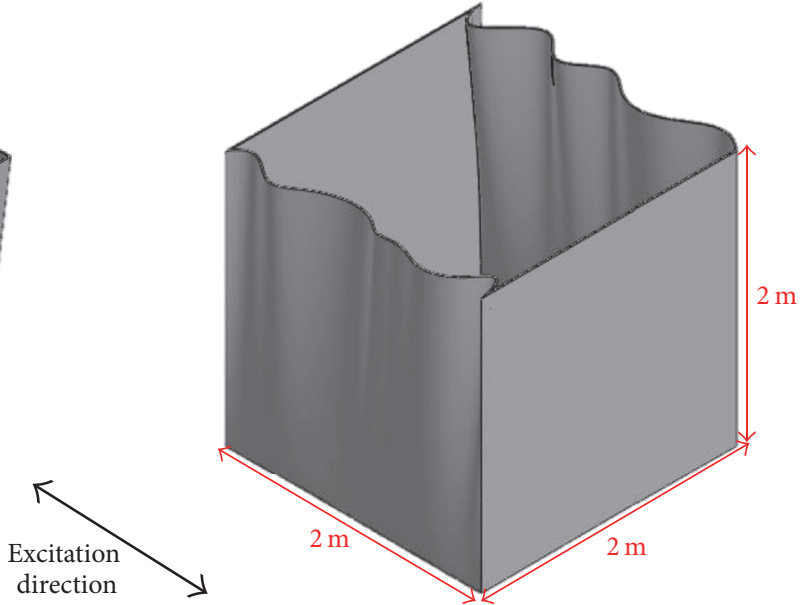

(b)

FIGURE 4: Size of the PVC fabric (a) before and (b) after being fitted into the laminar box.

box, while the top of the trapezium is about 1.25 times longer than the bottom (Figure 4(a)). The bottom of the fabric is clamped to the steel base of the box, while the top of the fabric is pegged to the top laminar layer. The result is a fabric system that has increasing leeway near the top of the box where the laminar layers are expected to move the most during testing (Figure 4(b)). This leeway allows the flexible membrane to fold/unfold easily to accommodate the movement of sand.

2.4. Preparation of the Sand. The laminar box was filled with $1 \mathrm{~m}$ depth of dry sand. This was achieved by raining the sand through a vertical distance higher than that required for the sand reaching terminal velocity (Figure 5(a)). Raining of sand is a common technique that is used to prepare sand samples for laboratory testing $[16,20]$. A number of studies were conducted to calibrate this technique [21-23]. It was reported that raining sand above the terminal falling height, determined to be above $400 \mathrm{~mm}$, would allow for consistency in relative density at various locations of the sand layer [21, 22]. In this study, a timber box with a base area of $2 \mathrm{~m} \times 2 \mathrm{~m}$ was used to rain the sand. The base of the box was drilled with 1800 holes of $9 \mathrm{~mm}$ diameter with $\mathrm{c} / \mathrm{c}$ spacing of $40 \mathrm{~mm}$. This means that $2.8 \%$ of the area of the base consists of openings (Figure 5(b)). During the raining process, the timber box was supported by the barrier columns of the laminar box. The maximum depth of sand in the laminar box is $2 \mathrm{~m}$, and thus the clear distance between the base of the raining box and the maximum elevation of the sand surface is $450 \mathrm{~mm}$. According to the data presented by both Rad and Tumay [22] and Vaid and Negussey [21], the relative density of the sand formed in the laminar box was about 35\%. Figure 5(c) shows the particle size distribution of the sand. The parameters of the sand used in this study are shown in Table 1 . The parameters were obtained according to NZS 4402 [24]. 


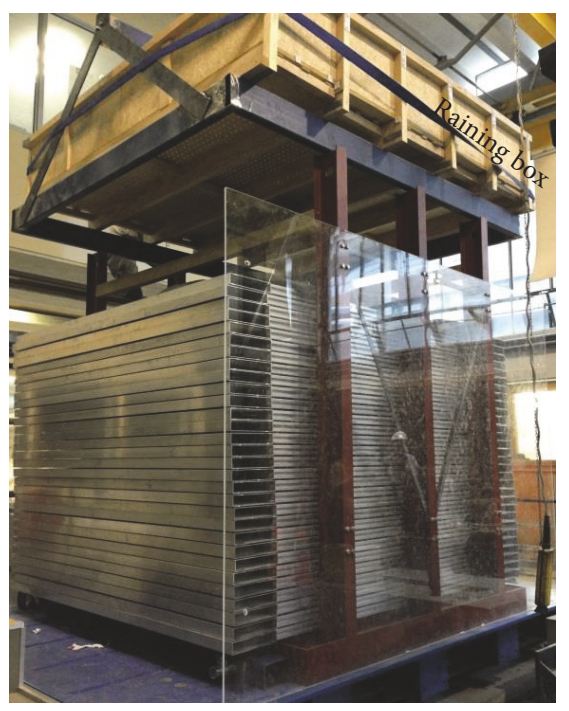

(a)

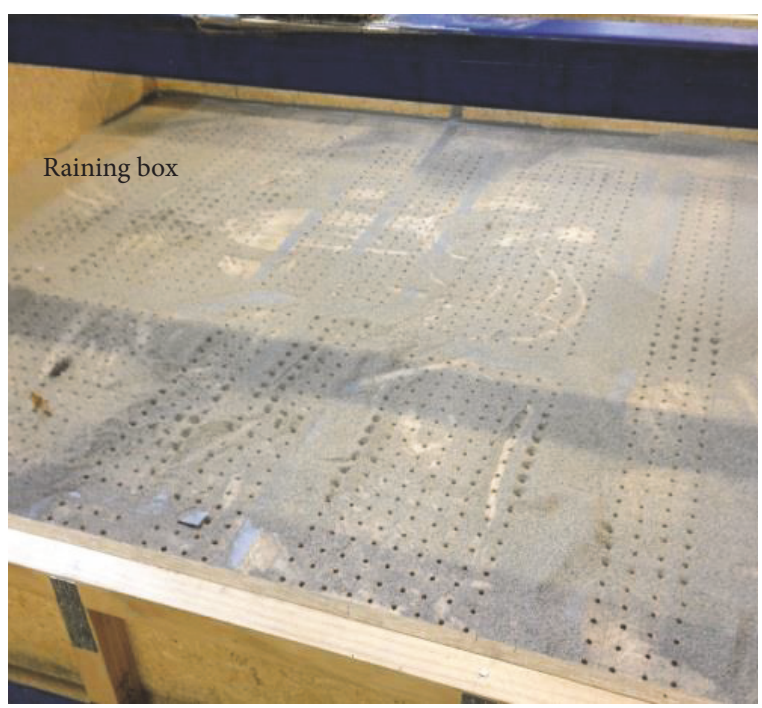

(b)

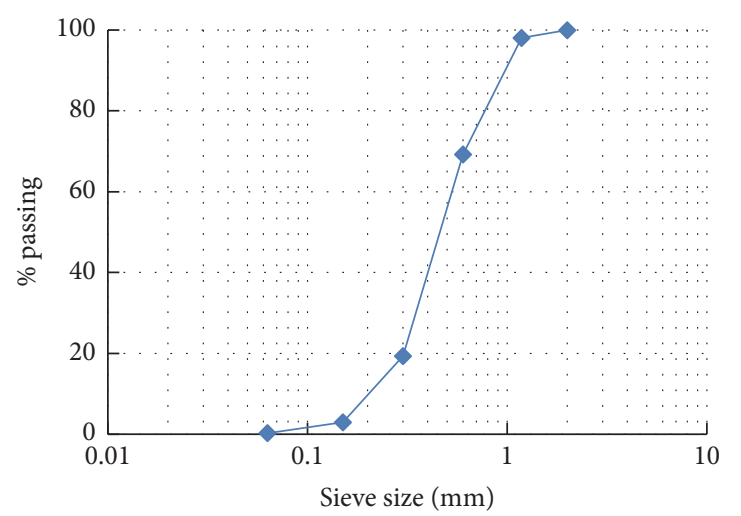

(c)

FIGURE 5: Test setup: (a) laminar box with (b) the raining box and (c) particle size distribution.

TABLE 1: Soil parameters.

\begin{tabular}{lc}
\hline Parameters & Quantities \\
\hline Density $(\rho)$ & $1451 \mathrm{~kg} / \mathrm{m}^{3}$ \\
Unit weight $(\gamma)$ & $14.2 \mathrm{kN} / \mathrm{m}^{3}$ \\
Max. void ratio $\left(e_{\max }\right)$ & 0.93 \\
Min. void ratio $\left(e_{\min }\right)$ & 0.6 \\
Specific gravity $\left(G_{s}\right)$ & 2.67 \\
\hline
\end{tabular}

2.5. Shake Table Test Setup. The laminar box with $1 \mathrm{~m}$ depth of sand was placed on the shake table as shown in Figure 6. A frame model was placed on the sand surface. The model was assumed to be a SDOF model with a fixed base fundamental frequency of $2.8 \mathrm{~Hz}$. The mass at the top was $19.2 \mathrm{~kg}$ and the height of the model was $580 \mathrm{~mm}$. The footing size was $475 \mathrm{~mm} \times 475 \mathrm{~mm}$. The footing was assumed to be rigid. Sand paper was attached under the footing to increase the friction at the footing-sand interface and thus minimise sliding. The accelerations at the top $\left(a_{T}\right)$ and at the footing $\left(a_{F}\right)$ of the model were measured. The acceleration of the sand beneath the model $\left(a_{S}\right)$ was measured by embedding another accelerometer in the sand directly beneath the centre of the footing of the model. Two laser transducers were used to measure the settlement at the sand surface and $250 \mathrm{~mm}$ away from the footing edge (Figure 6). The acceleration at the base of the laminar box $\left(a_{B}\right)$ was also recorded. Strain gauges were attached at the base of the columns to measure the strain for calculating the bending moment development. The bending moments were used to calculate the base shears $(V)$.

The excitation was simulated based on the Japanese Design Spectrum for a hard soil condition [25, 26]. Figure 7(a) shows the acceleration time history of the excitation. The peak ground acceleration (PGA) of the excitation is $0.79 \mathrm{~g}$. The shake table used for this study was displacement controlled with a maximum allowable movement of $\pm 120 \mathrm{~mm}$. The displacement time histories of the excitations were obtained by double integration of the acceleration time history (Figure 7(c)). Because the maximum ground displacement $(335.57 \mathrm{~mm})$ was larger than the allowable range of the shake table, it was decided to reduce the displacement of the excitation by a factor of four so that the maximum displacement of the ground motion is within the limit of the shake table. The ground acceleration is also reduced 

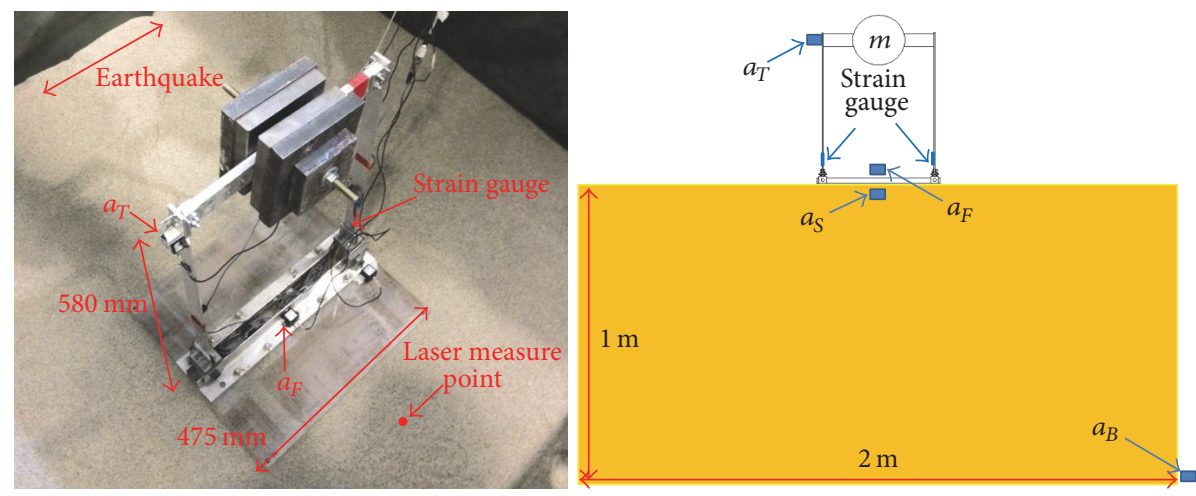

Figure 6: Setup of the model and instrumentation.

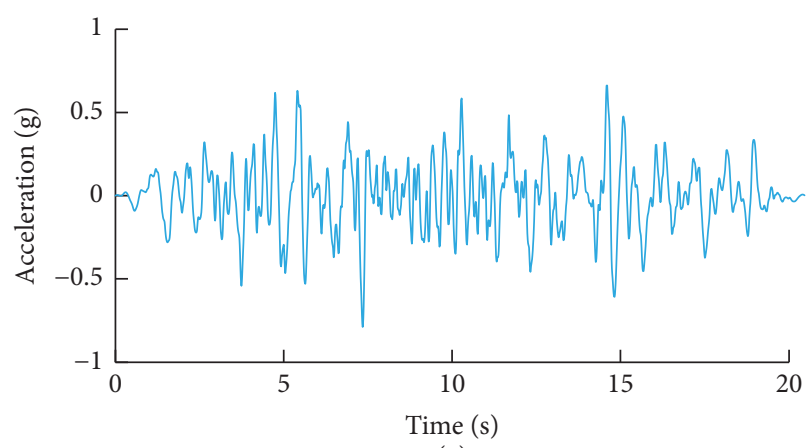

(a)

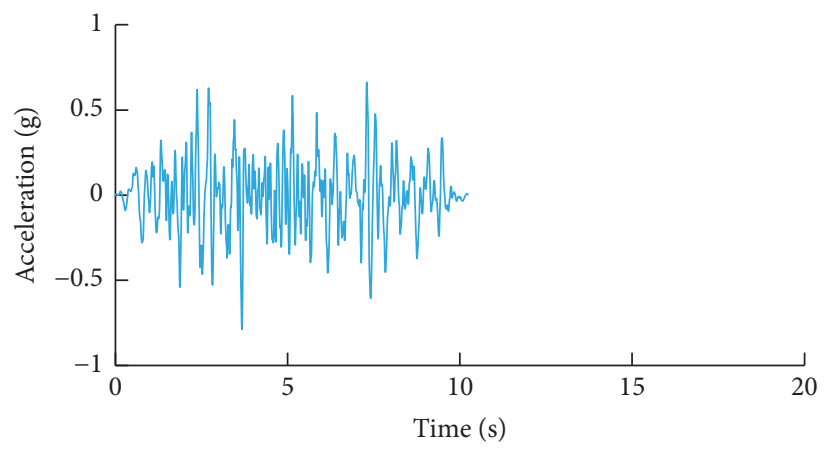

(b)

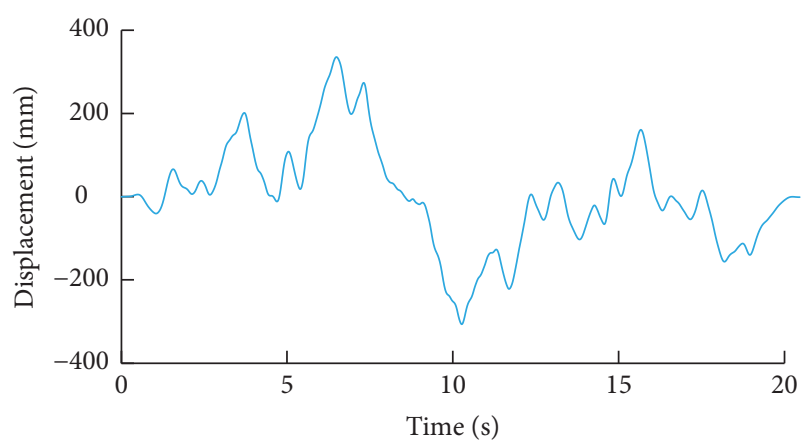

(c)

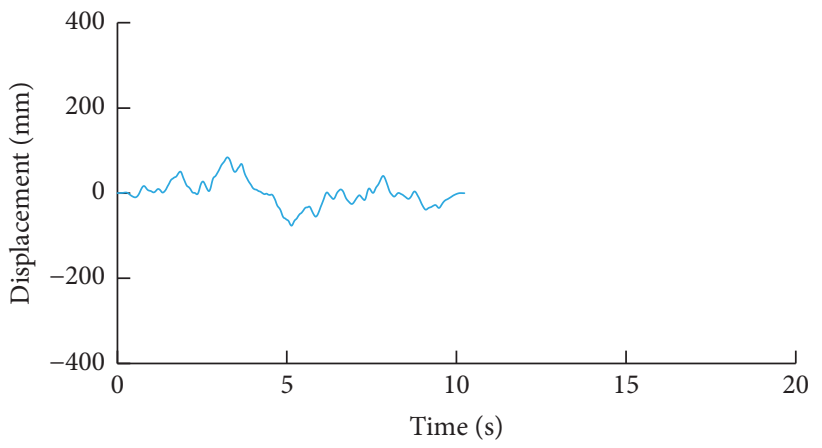

(d)

Figure 7: Ground excitation. ((a) and (c)) original and ((b) and (d)) scaled time history.

by a factor of four. The reduction leads to a loading that is not strong enough to excite the structure. To keep the magnitude of ground acceleration according to Buckingham $\pi$ theory [27], the scale factor of the duration of the ground excitation needs to be two, because the scale factor of the ground acceleration depends on the dimension length and the dimension time power two. The relationship between the scale factors of length $\left(S_{L}\right)$, times $\left(S_{T}\right)$, and acceleration $\left(S_{a}\right)$ is $S_{T}=\sqrt{S_{L} / S_{a}}$. To keep the acceleration magnitude, the acceleration scale factor needs to be 1 . Consequently, the scale factor for time is $\sqrt{4 / 1}=2$. After scaling, the magnitude of the ground displacement is only $25 \%$ of the original magnitude (see Figure $7(\mathrm{~d})$ ), while the magnitude of the ground acceleration time history has the same magnitude of the original ground acceleration (see Figure $7(\mathrm{~b})$ ). The duration of the ground excitation is only $50 \%$ of the original duration (see Figures $7(\mathrm{~b})$ and $7(\mathrm{~d})$ ). To investigate the effect of aftershock earthquake on the structure with soil, a sequence of three excitations was applied to the laminar box. The effect of mainshock was represented by the first excitation. The second and third excitations were used to represent the first and second aftershocks, respectively. For simplification, it is assumed that the time history of aftershocks is the same as that of the mainshock.

\section{Accelerations of the Structure, Footing, and Soil}

Figure 8 , derived from the mainshock, shows the response spectrum of accelerations at three different locations. The 


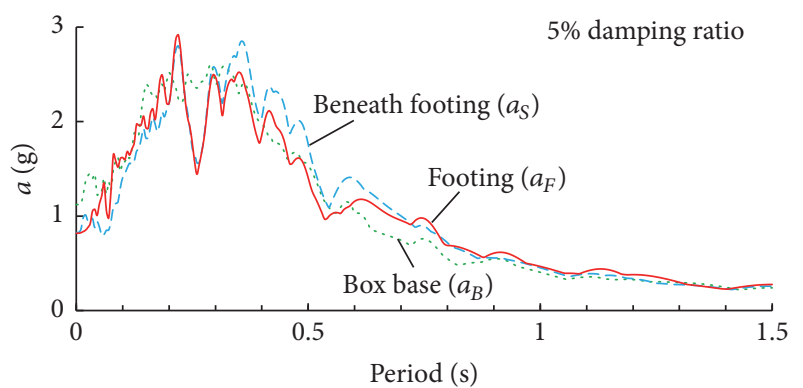

FIGURE 8: Response spectrum of accelerations at different locations.

dotted line represents the response spectrum at the base of the laminar box $\left(a_{B}\right)$. The dashed and solid lines are the response spectra of acceleration at the centre $\left(a_{F}\right)$ and immediately beneath $\left(a_{S}\right)$ the footing, respectively. In the long period range (greater than $0.3 \mathrm{~s}$ ), the spectrum values of $a_{S}$ are larger than those of $a_{B}$. In contract, in the short period range (less than $0.2 \mathrm{~s}$ ), the spectrum values of $a_{S}$ are lower than those of $a_{B}$.

Comparing the response spectrum of acceleration at the footing $\left(a_{F}\right)$ and under the footing $\left(a_{S}\right)$, the spectrum values of $a_{F}$ are higher than those of $a_{S}$ in the period range between $0.03 \mathrm{~s}$ and $0.2 \mathrm{~s}$. In the long period range (greater than $0.7 \mathrm{~s}$ ) the spectrum values of $a_{F}$ and $a_{S}$ are similar. Other than that, the spectrum values of $a_{F}$ are lower than those of $a_{S}$.

The difference between the response spectrum values of $a_{F}$ and $a_{S}$ can be attributed to the interaction between the response of the model, the footing, and the soil. A part of the footing was observed to be temporarily separated from the supporting soil during all experiments. Because of the separation, the response spectrum values of $a_{F}$ around the fixed base fundamental period of the model $(0.36 \mathrm{~s})$ reduce.

Figure 9(a) shows the acceleration of the soil beneath the model footing $\left(a_{S}\right)$ during the mainshock and the first aftershock. While the solid line represents the case of the mainshock, the dashed line illustrates that of the first aftershock. As shown, the amplitude of the soil acceleration due to the mainshock was larger than that due to the aftershock. The maximum sand acceleration beneath the footing due to mainshock and the first aftershock was $0.75 \mathrm{~g}$ and $0.62 \mathrm{~g}$, respectively, that is, a $17.33 \%$ difference. Figure 9(b) compares the acceleration of the soil beneath the model footing during the first (dotted line) and second (solid line) aftershocks. In general, the soil accelerations during the first and second aftershocks were similar. The maximum soil acceleration due to the second aftershock was $0.64 \mathrm{~g}$. The difference in maximum soil acceleration between the first and second aftershocks was only $0.02 \mathrm{~g}$. It is shown that acceleration of soil in the event of aftershocks is smaller than that in the mainshock, even though both mainshock and aftershocks have the same magnitude.

Figure 10 compares the response spectrum of the soil acceleration $\left(a_{S}\right)$ under the footing during the mainshock and the aftershocks. The response spectra of $a_{S}$ obtained from the aftershocks are very similar. However, some notable differences can be found when these response spectra are compared to those obtained from the mainshock. At periods around $0.35 \mathrm{~s}$ and $0.6 \mathrm{~s}$, the spectrum accelerations from the mainshock are higher than those of the aftershocks.

The difference in the response spectrum value of $a_{S}$ among tests is attributed to the soil density being much higher in the aftershock events. Extensive soil settlement took place during the mainshock, and thus the soil density increased. Figure 11 shows the settlement at the soil surface in the mainshock and aftershocks. As shown, the final settlement at the soil surface due to the mainshock was $42.8 \mathrm{~mm}$, while the final settlement caused by the first and second aftershocks was $7.4 \mathrm{~mm}$ and $6.2 \mathrm{~mm}$, respectively. Most of the soil settlement took place during the mainshock. Thus, the soil densities in the events of the aftershocks were much higher than those of the mainshock. In the aftershocks, the settlements at the soil surface were very similar, leading to approximately equal changes of soil density. Consequently, the response spectrum values of $a_{S}$ in the first and second aftershocks were similar (Figure 10). With lower soil density in the mainshock, the soil had the largest spectrum amplitude for periods in the vicinity of the fixed base fundamental period $(0.36 \mathrm{~s})$ of the structure.

Figure 12 compares the horizontal acceleration developed at the footing $\left(a_{F}\right)$ during the mainshock and aftershocks. While Figure 12(a) shows the effect of aftershock by comparing the footing response obtained from the mainshock and the first aftershock, Figure 12(b) illustrates the effect of subsequent aftershock on the footing acceleration. Although the excitations were the same, the developments of footing acceleration during the mainshock and the first and the second aftershocks were different from each other. Figure 13 shows the response spectrum of soil and footing accelerations $a_{S}$ and $a_{F}$ obtained from the aftershocks. For most periods, the spectrum values of $a_{F}$ are close to or larger than those of $a_{S}$. Except in the period range (approximately $0.3 \mathrm{~s}$ and $0.6 \mathrm{~s}$ ) covering the fixed base fundamental period of the model $(0.36 \mathrm{~s})$, the spectrum value of $a_{F}$ is smaller than that of $a_{S}$. This finding is consistent with the results of the mainshock.

Figure 14 shows a comparison of the horizontal acceleration at the top of the model $\left(a_{T}\right)$. The acceleration of the model during the mainshock was larger than that during the aftershocks. The maximum horizontal acceleration at the top of the model in the mainshock and the first aftershock was $0.92 \mathrm{~g}$ and $0.67 \mathrm{~g}$, respectively, that is, a $27 \%$ difference. On the other hand, the maximum horizontal acceleration at the top of the model during second aftershock was $0.68 \mathrm{~g}$, similar to that of the first aftershock (see Figure 15(b)). The results show that, in the event of the aftershocks, the response of structure with SFSI can be reduced. This could be attributed to the fact that the density of sand of the aftershock was greater than that of the mainshock.

Figure 15 shows the Fourier spectrum of the structural horizontal acceleration due to the mainshock and the aftershocks. There is a noticeable difference between the Fourier amplitude of the mainshock and that of the first aftershock (Figure 15(a)). The maximum Fourier amplitude for case of the mainshock is 1.11 gs. However, the maximum Fourier amplitude obtained from the first aftershock was significantly lower (only $0.78 \mathrm{gs}$ ). Also, the majority of the Fourier amplitudes within the range of $1.6 \mathrm{~Hz}$ and $3 \mathrm{~Hz}$ obtained from the first aftershock were lower than those from 


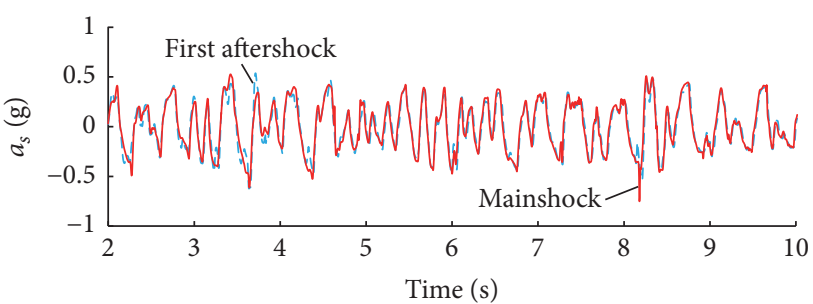

(a)

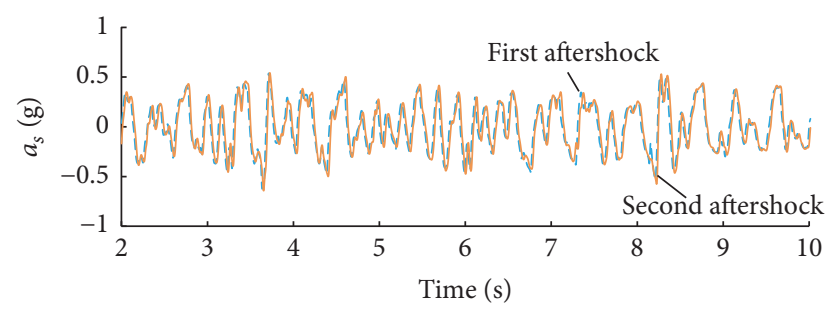

(b)

FIGURE 9: Effect of the earthquake sequence on the soil acceleration from beneath the footing.

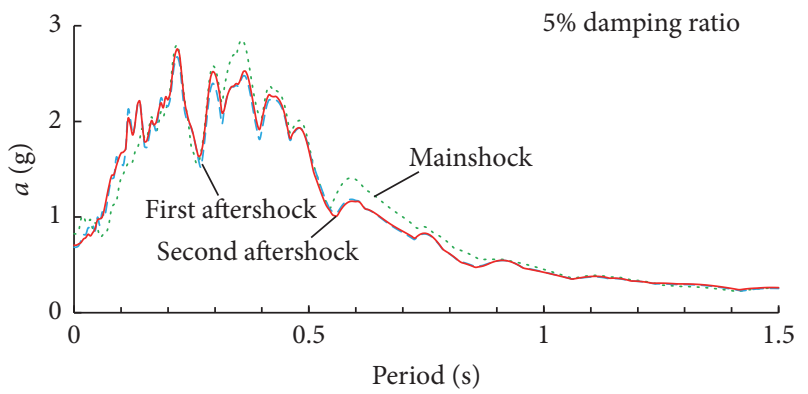

FIGURE 10: Effect of soil density on the spectrum acceleration of $a_{S}$.

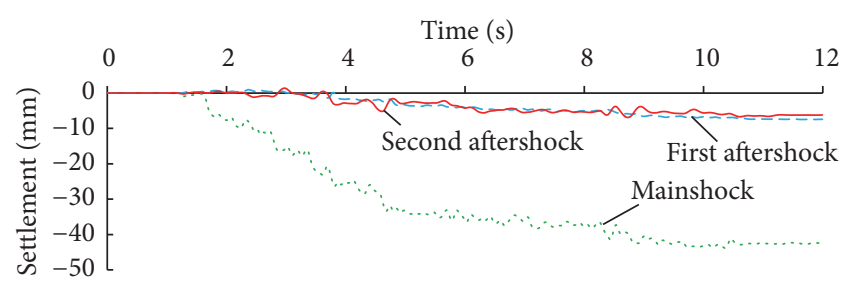

Figure 11: Settlement of the soil surface during the mainshock and aftershocks.

the mainshock. The Fourier amplitude obtained from the first aftershock was also significantly different from that obtained using the second aftershock (Figure 15(b)). This result shows that although the excitations of the mainshock and the first and the second aftershocks were assumed to be the same, the aftershock can cause amplification or reduction on the response of structure with SFSI.

\section{Calculating the Base Shear of the Structure with SFSI}

Strain gauge was used to measure the strain at the column base of the model. The development of base shear in the model during the earthquake can be calculated using the strain gauge measurement. Figure 16 shows a comparison of the base shear development in the model due to the mainshock and the aftershocks. As shown, the maximum base shear in the model due to the mainshock was larger than that due to the first aftershock. On the other hand, although the maximum horizontal acceleration at the top of the model due to the mainshock was the largest, the largest maximum base shear $(V)$ was found in the second aftershock event (Figure 16). The maximum base shear due to the mainshock was $169.5 \mathrm{~N}$. The maximum base shear due to the first and second aftershocks was $159.2 \mathrm{~N}$ and $179 \mathrm{~N}$, respectively. The maximum base shear due to the second aftershock was 5.6\% and $12.4 \%$ larger than that due to the mainshock and the first aftershock, respectively. Although the mainshock and aftershock were the same, the development of maximum acceleration and base shear shows a different trend when subjected to the mainshock and the aftershocks.

Chopra and Yim [28] developed an equation of motion to calculate the response of a structure with a flexible support. The deformation of the support was modelled using twospring support. They developed a set of formulas to calculate the maximum base shear $\left(V_{\max }\right)$ of structures on flexible supports:

$$
\begin{aligned}
& V_{\max }=V_{\mathrm{cr}}\left\{\frac{h^{2}}{R_{o}^{2}}\right. \\
& \left.+e^{-\xi \phi} \sqrt{\frac{b^{4}}{R_{o}{ }^{4}}+\frac{b^{2}}{R_{o}{ }^{2}}\left[\left(\frac{\widetilde{S}_{a}}{g}\right)^{2}\left(\frac{h}{b}\right)^{2} e^{\xi \pi}-1\right]}\right\} \text {, }
\end{aligned}
$$

where

$$
\phi=\frac{\pi}{2}-\tan ^{-1}\left\{\frac{b}{R_{o}}\left[\left(\frac{\widetilde{S}_{a}}{g}\right)^{2}\left(\frac{h}{b}\right)^{2} e^{\xi \pi}-1\right]^{-\frac{1}{2}}\right\} ;
$$

and $b$ is half of the base width and $h$ is the height of the model; $g$ is the gravitational acceleration; $R_{o}=\sqrt{h^{2}+b^{2}}$ and $V_{\mathrm{cr}}=m g \times b / h$ is the base shear to initial footing uplift. $\widetilde{S}_{a}$ is the spectrum acceleration corresponding to the effective vibration period $\widetilde{T}$.

The effective vibration period of a structure with a flexible support is

$$
\widetilde{T}=T \sqrt{1+\frac{k h}{k_{\theta}}},
$$

where $T$ is the fundamental period of the structure with a fixed base, $k$ is the lateral bending stiffness of structure, and 


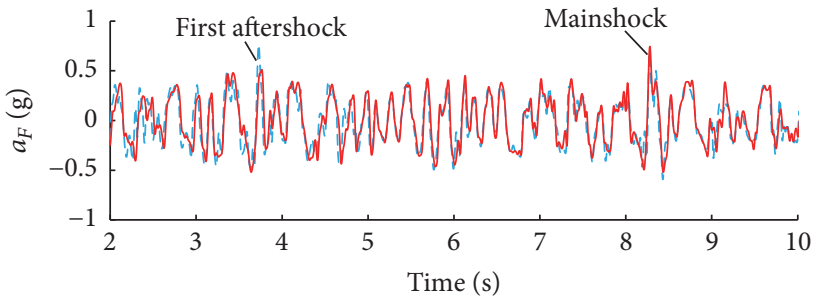

(a)

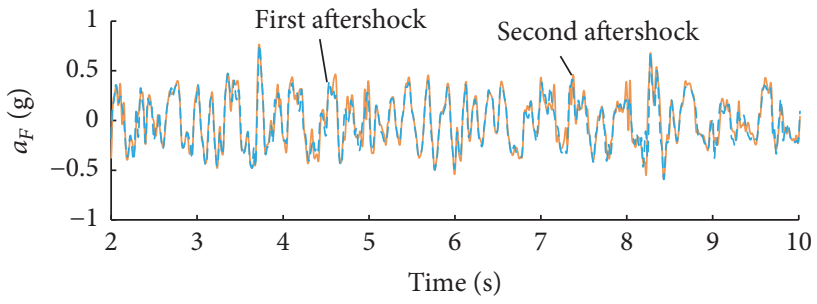

(b)

FIGURE 12: Effect of aftershock on the footing acceleration.

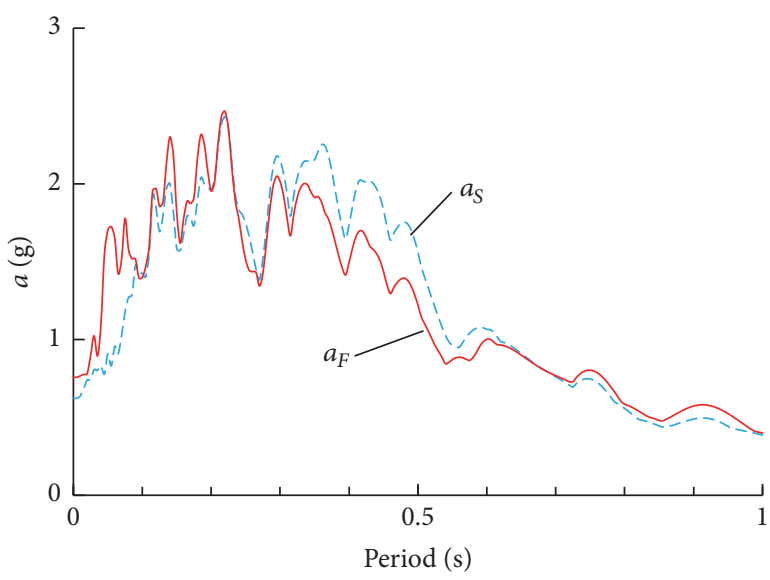

(a)

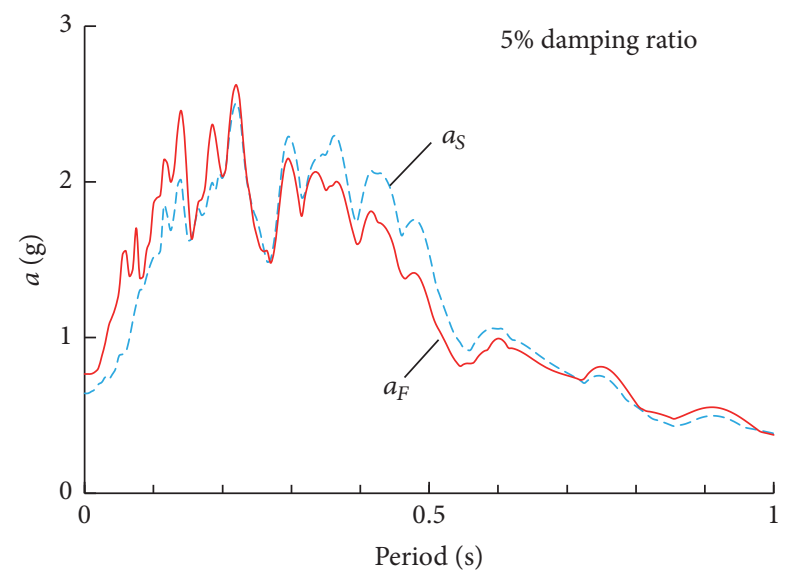

(b)

FIGURE 13: Response spectrum of soil and footing accelerations obtained from (a) the first aftershock and (b) the second aftershock.

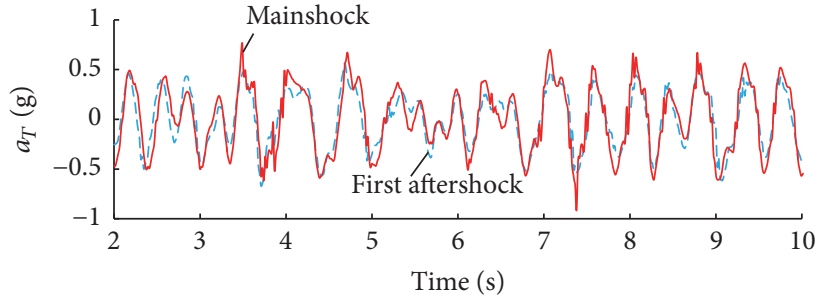

(a)

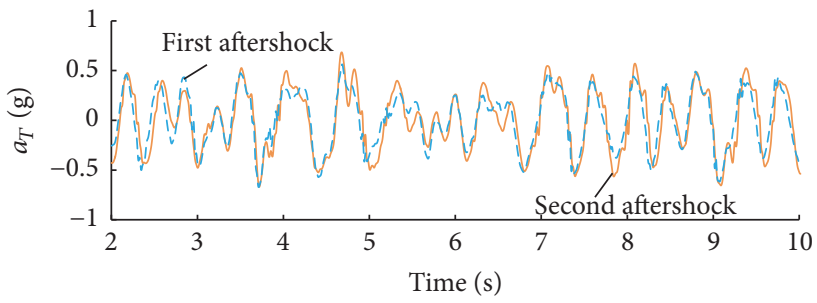

(b)

FIGURE 14: Effect of aftershocks on the structural acceleration.

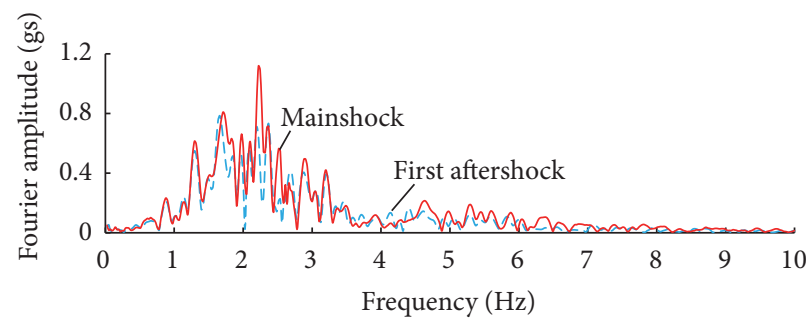

(a)

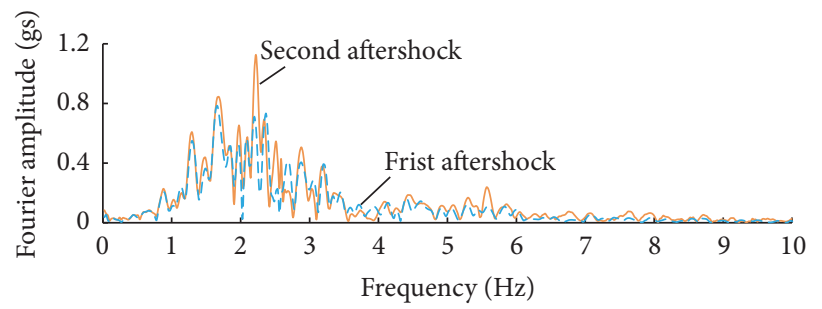

(b)

FIGURE 15: Frequencies content of structural top accelerations. 


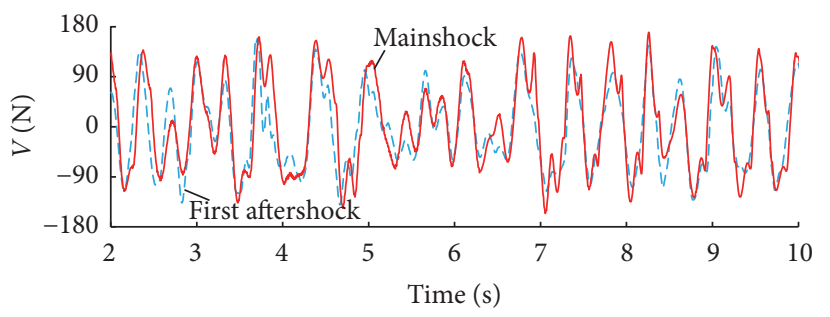

(a)

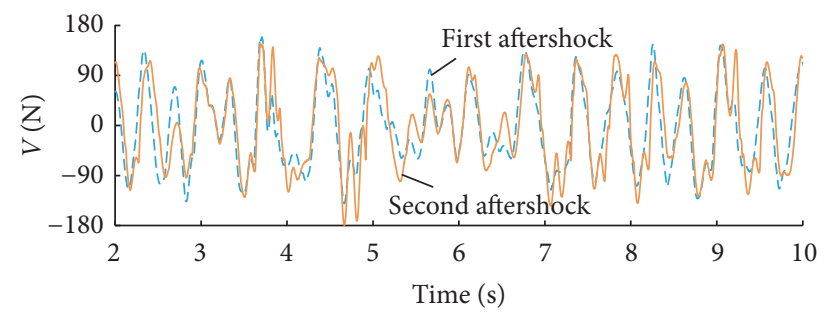

(b)

FIgURE 16: Base shear in the structure due to the mainshock and aftershocks.

$k_{\theta}$ is the rotational assumed static stiffness of the footing on uniform soil:

$$
k_{\theta}=\frac{G \pi}{8(1-v)} B^{2},
$$

where $G$ and $v$ are the shear modulus and Poisson's ratio of the soil, respectively; $B$ is the base width $(2 b)$.

An empirical equation was developed by Larkin [29] such that the shear wave velocity $\left(V_{s}\right)$ of sand can be calculated using the relative density $\left(D_{r}\right)$, mass density $(\rho)$, and mean effective confining stress $\left(\sigma_{M}^{\prime}\right)$ :

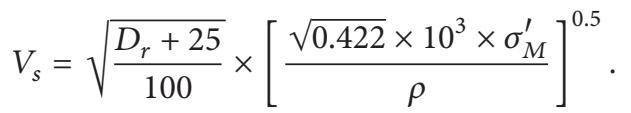

The shear wave velocity can be used to calculate the shear modulus of soil:

$$
G=\rho V_{s}^{2} .
$$

By combining (5) and (6), (7) can be obtained to estimate the shear modulus $(G)$ of sand using the relative density $D_{r}$ and effective confining stress $\sigma_{M}^{\prime}$ :

$$
G=\frac{D_{r}+25}{100} \times \sqrt{0.422} \times 10^{3} \times \sigma_{M}^{\prime} .
$$

The shear modulus of the sand at depth of $59 \mathrm{~mm}$ is $0.45 \mathrm{MPa}$. This depth, calculated from $1 / 8$ of the footing width, is the appropriate depth for a characteristic soil element to represent the stress conditions of soil involved in providing resistance to moment and shear [3]. The effective vibration frequency of the model on sand is calculated to be $2.74 \mathrm{~Hz}$ (see (3)). The effective vibration period of the model is very similar to the fixed base fundamental period. This is because, in shake table experiments, the sand cannot be scaled. As a consequence of this, the sand has larger stiffness than that of scaled sand. Consequently, the unscaled sand has a higher shear modulus, that is, higher sand stiffness.

Figure 17 shows a comparison of the maximum base shear $\left(V_{\max }\right)$ of the model obtained using experimental data and (1). Strain gauge measurements are used to determine the maximum bending moment at the base of the model and thus the experimental maximum base shear can be calculated. The spectrum acceleration $\widetilde{S}_{a}(\widetilde{T})$ is derived from the acceleration measured in the soil beneath the footing (Figure 10). It

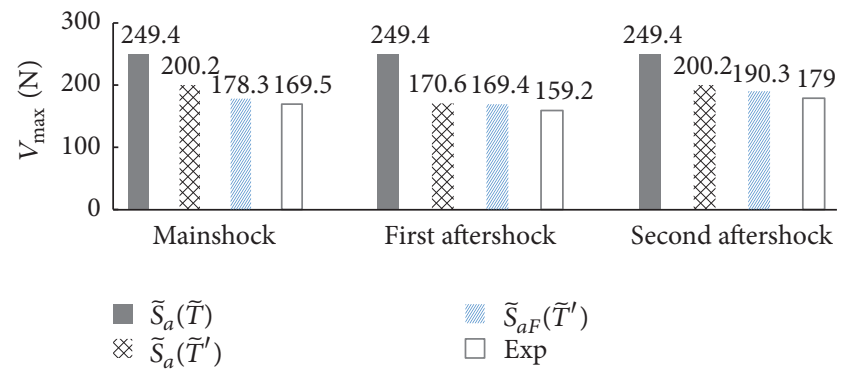

FIGURE 17: Calculation of the maximum base shear.

can be seen that (1) overestimates the maximum base shear of the model. The experimentally obtained maximum base shear for the model due to the mainshock and the first and the second aftershocks is $169.5 \mathrm{~N}, 159.2 \mathrm{~N}$, and $179.0 \mathrm{~N}$, respectively. With (1), the corresponding maximum base shear is $249.4 \mathrm{~N}$. Equation (1) overestimates the maximum base shear of model by $47 \%, 57 \%$, and $39 \%$, respectively.

The accuracy of (1) is associated with the estimation of the effective vibration period of the model on sand. In (3), the rotational stiffness of footing on soil is modelled using elastic springs. Footing uplift and soil plastic deformation are not considered. Therefore, the effective vibrational period of the model is underestimated.

As shown in Figure 15, the maximum Fourier amplitude is found at $2.22 \mathrm{~Hz}$ considering the mainshock and the second aftershock. This indicates that the corresponding vibration periods $\left(\widetilde{T}^{\prime}\right)$ are $0.45 \mathrm{~s}$. Compared to the theoretical calculation $(\widetilde{T}=0.36 \mathrm{~s})$, (3) underestimates the effective vibration period by $20 \%$. For the case of the first aftershock, the maximum Fourier amplitude is found at $1.64 \mathrm{~Hz}$, that is, $26 \%$ lower than that in the case of the mainshock. When $\widetilde{T}^{\prime}$ is used to obtain the spectrum value, the accuracy of (1) can be improved. The maximum base shear of the model due to the mainshock and the aftershocks, estimated using $\widetilde{S}_{a}\left(\widetilde{T}^{\prime}\right)$, is $200.2 \mathrm{~N}, 170.6 \mathrm{~N}$, and $200.2 \mathrm{~N}$, respectively. Although (1) overestimates the maximum base shears by $18 \%, 7 \%$, and $12 \%$, the calculations are closer to the experimental results. To further improve the accuracy of (1), the spectrum acceleration derived using footing acceleration $\left(a_{F}\right)$ in conjunction with $\widetilde{T}^{\prime}$ can be used. The maximum base shear obtained from (1) using $\widetilde{T}^{\prime}\left(\widetilde{T}^{\prime}\right)$ is $178.3 \mathrm{~N}, 169.4 \mathrm{~N}$, and $190.3 \mathrm{~N}$ for the case of the mainshock, the first aftershock, and the second aftershock, 
respectively. The corresponding errors reduce to $5 \%, 6 \%$, and $6 \%$.

\section{Conclusions}

This work addresses the response of a model structure on sand using a large laminar box which is square in plan. The laminar box can accommodate a depth of $2 \mathrm{~m}$ of soil, with a surface area of $4 \mathrm{~m}^{2}$. The design and construction of the relatively large laminar box are presented. Shake table tests are conducted. An excitation was applied three times to simulate the effect of the mainshock and aftershocks of an earthquake.

The results reveal the following:

(i) A relatively large laminar box can be used to investigate the structural response with SFSI and produce meaningful outcomes.

(ii) The development of soil settlement in the mainshock was much larger than that in the aftershocks. As a result, the development of spectrum acceleration of soil acceleration was affected.

(iii) Although the mainshock and aftershock were assumed to be the same, the densification of the sand in the aftershocks affects the development of structural top accelerations.

(iv) With SFSI, the maximum horizontal acceleration in the structure when subjected to the mainshock was larger than that due to the aftershock. However, the maximum base shear of structure due to the aftershock can be larger than that due to the mainshock.

(v) When comparing experimental results against those from an existing theoretical method, the accuracy of the method is sensitive to the effective vibration period of the SFSI system and the spectrum acceleration of the footing.

\section{Disclosure}

This paper is part of the doctoral thesis of Xiaoyang Qin.

\section{Conflicts of Interest}

The authors declare that they have no conflicts of interest.

\section{Acknowledgments}

The authors are grateful for the support by the Ministry of Business, Innovation and Employment through the Natural Hazards Research Platform under the Award 3708936 and by the Earthquake Commission under the Award 3704188.

\section{References}

[1] P. W. Taylor, P. E. Bartlett, and P. R. Wiessing, "Foundation rocking under earthquake loading," in Proceeding of the 10th International Conference on Soil Mechanics and Foundation Engineering, vol. 3, pp. 313-322, Stockholm, Sweden, 1981.
[2] A. S. Veletsos and J. W. Meek, "Dynamic behaviour of buildingfoundation systems," Earthquake Engineering \& Structural Dynamics, vol. 3, no. 2, pp. 121-138, 1974.

[3] T. Larkin, "Seismic response of liquid storage tanks incorporating soil structure interaction," Journal of Geotechnical and Geoenvironmental Engineering, vol. 134, no. 12, pp. 1804-1814, 2008.

[4] L. Deng, T. Algie, and B. L. Kutter, "Innovative economical foundations with improved performance that is less sensitive to site conditions: centrifuge data report for LJD01," Tech. Rep. UCD/CGMDR-09/01, University of California, Davis, Calif, USA, 2009.

[5] L. Deng, B. L. Kutter, and S. K. Kunnath, "Centrifuge modeling of bridge systems designed for rocking foundations," Journal of Geotechnical and Geoenvironmental Engineering, vol. 138, no. 3, pp. 335-344, 2012.

[6] T. B. Algie, M. J. Pender, R. P. Orense, and L. M. Wotherspoon, "Dynamic field testing of shallow foundations subject to rocking," in Proceedings of the New Zealand Society for Earthquake Engineering Annual Conference, Wellington, New Zealand, 2010.

[7] N. Saxena, D. K. Paul, and R. Kumar, "Effects of slip and separation on seismic SSI response of nuclear reactor building," Nuclear Engineering and Design, vol. 241, no. 1, pp. 12-17, 2011.

[8] M. Ormeño, T. Larkin, and N. Chouw, "Evaluation of seismic ground motion scaling procedures for linear time-history analysis of liquid storage tanks," Engineering Structures, vol. 102, pp. 266-277, 2015.

[9] M. Ormeño, M. Geddes, T. Larkin, and N. Chouw, "Experimental study of slip-friction connectors for controlling the maximum seismic demand on a liquid storage tank, Engineering Structures, vol. 103, pp. 134-146, 2015.

[10] M. Ormeño, T. Larkin, and N. Chouw, "The effect of seismic uplift on the shell stresses of liquid-storage tanks," Earthquake Engineering \& Structural Dynamics, vol. 44, no. 12, pp. 19791996, 2015.

[11] Y. Chen, T. Larkin, and N. Chouw, "Experimental assessment of contact forces on a rigid base following footing uplift," Earthquake Engineering \& Structural Dynamics, vol. 46, no. 1, pp. 1835-1854, 2017.

[12] X. Qin, Y. Chen, and N. Chouw, "Effect of uplift and soil nonlinearity on plastic hinge development and induced vibrations in structures," Advances in Structural Engineering, vol. 16, no. 1, pp. 135-147, 2013.

[13] T. Larkin, X. Qin, and N. Chouw, "Effect of local site on SFSI of clustered structure," in Proceedings of the International Workshop on Natural Hazards, Azores, Portugal, April 2016.

[14] X. Qin, Experimental studies of SFSI effect on upliftable structures [Doctoral dissertation], ResearchSpace, Auckland, New Zealand, 2016, https://researchspace.auckland.ac.nz/handle/2292/ 29301.

[15] G. M. Latha and A. M. Krishna, "Seismic response of reinforced soil retaining wall models: influence of backfill relative density," Geotextiles and Geomembranes, vol. 26, no. 4, pp. 335-349, 2008.

[16] T.-S. Ueng, M.-H. Wang, M.-H. Chen, C.-H. Chen, and L.H. Peng, "A large biaxial shear box for shaking table test on saturated sand," Geotechnical Testing Journal, vol. 29, no. 1, pp. $1-8,2006$.

[17] S. K. Prasad, I. Towhata, G. P. Chandradhara, and P. Nanjundaswamy, "Shaking table tests in earthquake geotechnical engineering," Current Science, vol. 87, no. 10, pp. 1398-1404, 2004 . 
[18] N. Mononobe and O. Matsuo, "On the determination of earth pressure during earthquakes," in Proceedings of the World Engineering Congress, vol. 9, pp. 179-187, Tokyo, Japan, 1929.

[19] M. Matsuo and S. Ohara, "Lateral earth pressures and stability of quay walls during earthquakes," in Proceedings of the 2nd World Conference on Earthquake Engineering, Tokyo, Japan, 1960.

[20] X. Qin, W. M. Cheung, N. Chouw, T. Larkin, and S. W. C. Ching, "Study of soil-structure interaction effect on ground movement using a laminar box," in Proceedings of the New Zealand Society for Earthquake Engineering Annual Conference, Wellington, New Zealand, 2013.

[21] Y. P. Vaid and D. Negussey, "Relative density of pluviated sand samples," Japanese Society of Soil Mechanics and Foundation Engineering, vol. 24, no. 2, pp. 101-105, 1984.

[22] N. S. Rad and M. T. Tumay, "Factors affecting sand specimen preparation by raining," ASTM Geotechnical Testing Journal, vol. 10, no. 1, pp. 31-37, 1987.

[23] M. Okamoto and S. Fityus, "An evaluation of the dry pluviation preparation technique applied to silica sand samples," in Proceedings of the International Symposium on Geomechanics and Geotechnics of Particulate Media, pp. 33-39, Taylor and Francis, London, UK.

[24] NZS 4402, Methods of Testing Soil for Civil Engineering Purposes, Standard Association of New Zealand, Wellington, New Zealand.

[25] Japan Society of Civil Engineers, Earthquake Resistant Design Codes in Japan, Maruzen, Tokyo, Japan, 2000.

[26] N. Chouw and H. Hao, "Study of SSI and non-uniform ground motion effect on pounding between bridge girders," Soil Dynamics and Earthquake Engineering, vol. 25, no. 7-10, pp. 717728, 2005.

[27] E. Buckingham, "On physically similar systems; Illustrations of the use of dimensional equations," Physical Review A: Atomic, Molecular and Optical Physics, vol. 4, no. 4, pp. 345-376, 1914.

[28] A. K. Chopra and S. C.-S. Yim, "Simplified earthquake analysis of structures with foundation uplift," Journal of Structural Engineering (United States), vol. 111, no. 4, pp. 906-930, 1985.

[29] T. Larkin, "DENSOR-a computer program for seismic response analysis of nonlinear horizontal soil layers," Tech. Rep. 51508/6, Norwegian Geotechnical Institute, 1978. 


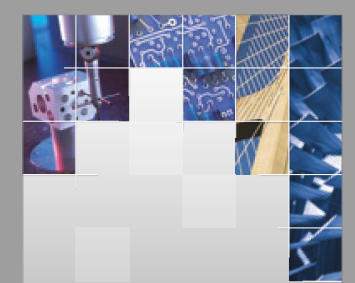

\section{Enfincering}
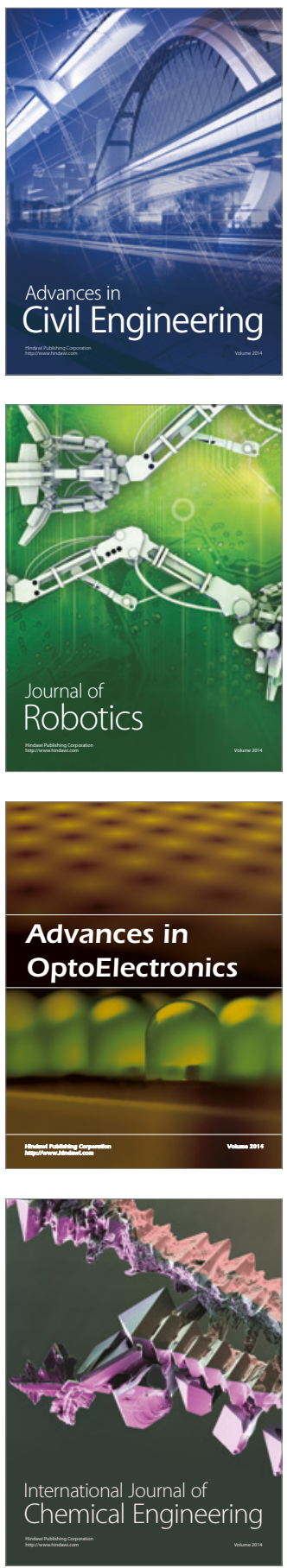

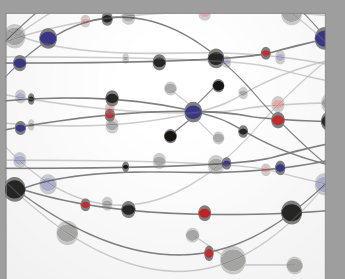

The Scientific World Journal

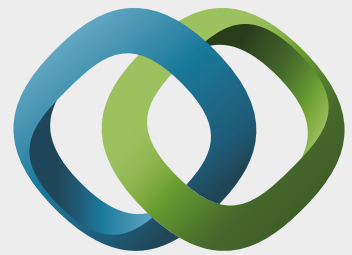

\section{Hindawi}

Submit your manuscripts at

https://www.hindawi.com
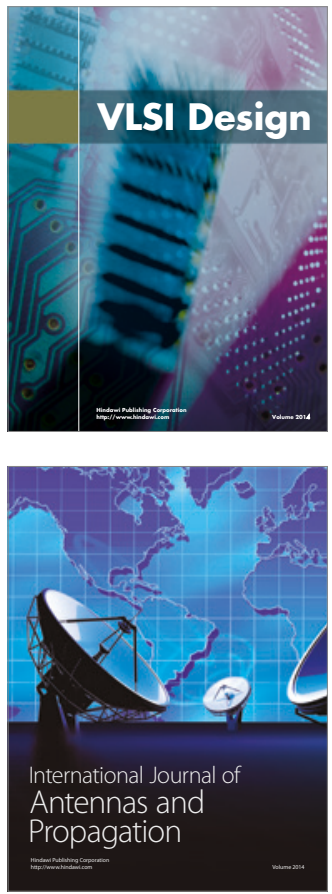

\section{Rotating}

Machinery
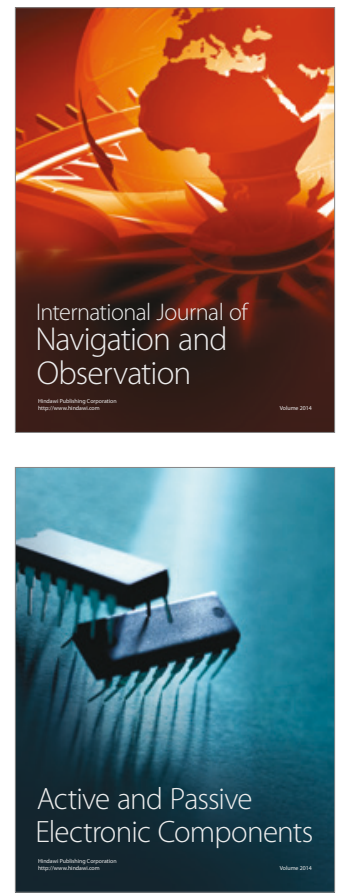
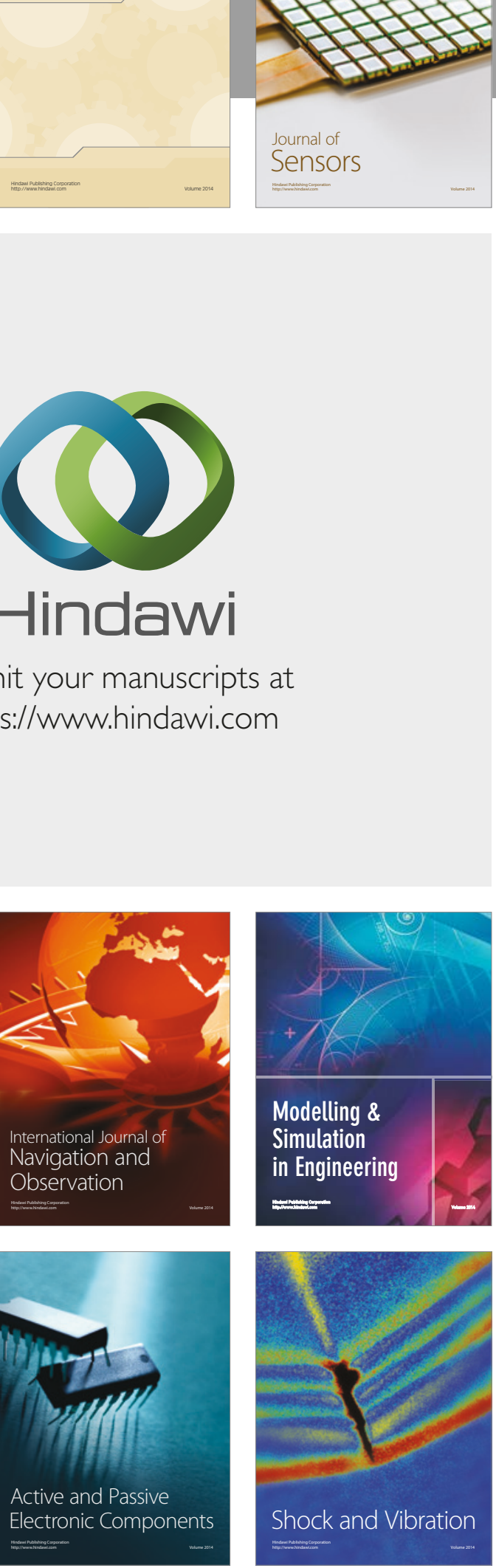
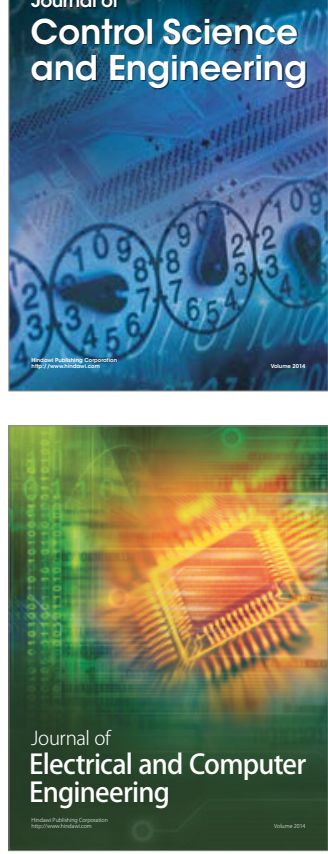

Distributed

Journal of

Control Science

and Engineering
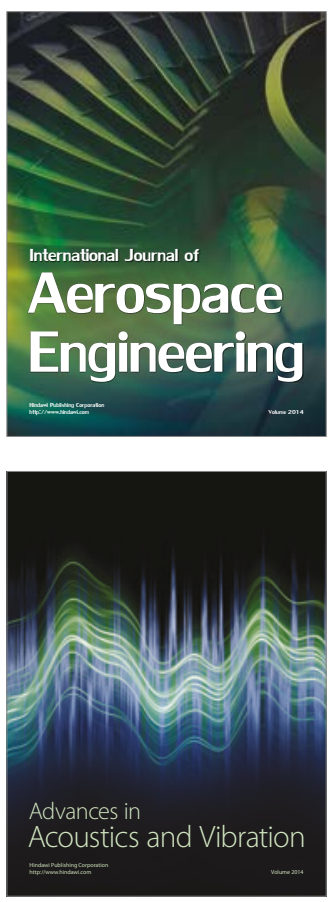

Sensor Networks 